\title{
The Effect of Tripolyphosphate (TPP) Volumes on the Synthesis of Chitosan Nanoparticles Using Ionic Gelation Method
}

\author{
Y Amri*, R Fajri \\ Department of Chemistry \\ Universitas Samudra \\ Langsa, Indonesia \\ *yulidaamri@unsam.ac.id \\ P Novitasari \\ Department of Chemistry \\ Universitas Samudra \\ Langsa, Indonesia
}

\author{
Fitriani \\ Department of Biology \\ Universitas Samudra \\ Langsa, Indonesia
}

\author{
M Zulfajri \\ Department of Chemistry Education \\ Universitas Serambi Mekkah \\ Aceh, Indonesia
}

\begin{abstract}
The effect of different volumes of tripolyphosphate (TPP) on the synthesis of chitosan nanoparticles (NPs) was evaluated. The synthesis was performed using the ionic gelation method with a $0.5 \%$ chitosan solution and $1 \%$ TPP. A particle size analyser (PSA) was used to obtain the size of the chitosan NPs while a Fourier Transform Infrared (FTIR) spectrophotometer was utilized to explore the functional groups of the NPs. The results showed that the average size of chitosan NPs were $648.2 \mathrm{~nm}(20: 4), 515.7 \mathrm{~nm}, 648.2 \mathrm{~nm}, 515.7 \mathrm{~nm}$, and $340.3 \mathrm{~nm}$ for different volume ratios of 20:4, 20:3, and 20:2, respectively. Less TPP volume was added, the smaller the particle size will be produced. The chitosan NPs have several functional groups including $-\mathrm{OH}$, amines, $-\mathrm{CH}$ alkanes, $-\mathrm{C}=\mathrm{O}$ groups, amides, $\mathrm{P}-\mathrm{O}$ groups, and $\mathrm{P}=\mathrm{O}$ groups, indicating that the synthesis product corresponded to the chitosan-TPP compound.
\end{abstract}

Keywords-ripolyphosphate, chitosan nanoparticles, ionic gelation method

\section{INTRODUCTION}

Langsa city has many marine resources including fish, crab, and shrimp. After consuming the crab and shrimp, their shells are usually disposed as a waste. The outer shells of crab and shrimp can be used as a source of chitosan as a natural biopolymer [1]. In previous study, chitosan has been produced from white shrimp shells [1]. Chitosan substance can be converted into chitosan NPs with many advantages. Chitosan NPs can be used as a delivery agent for drugs [2,3], proteins [4] and antigens [5]. They also have antifungal [6] and antimicrobial activity [7]. Besides, chitosan NPs have been applied for the removal of metal ions and could serve as a promising adsorbent in wastewater treatment [8]. Therefore, it is important to study several parameters that can affect the characteristics of the chitosan NPs.

The NPs can be synthesized through two approaches; topdown and bottom-up approaches [9]. The top-down approach reduces the size of bulk materials to nanoscale by grinding or etching while the bottom-up approach is the synthesis of nanoparticles involving chemical reactions from small (bio)molecules [10]. Based on previous studies, there were several methods involving chemical reactions in the preparation of the NPs. They are sonochemical method $[11,12]$, ionic gelation method $[13,14]$ and polyelectrolyte complexation method [14]. In this study, chitosan NPs were prepared using ionic gelation method with various volume ratios of chitosan/TPP to evaluate the effect of TPP solution in the synthesis of chitosan NPs.

\section{MATERIALS AND METHODS}

\section{A. Equipments}

The equipment used in this research were glassware, centrifuge, hotplate, analytical balance, magnetic stirrer, Fourier Transform Infrared (FTIR) spectrophotometer, and Particle Size Analyzer (PSA).

\section{B. Materials}

Sodium tripolyphosphate (NaTPP) and acetic acid $\left(\mathrm{CH}_{3} \mathrm{COOH}\right)$ were purchased from $\mathrm{CV}$. Multi Kreasi Bersama, Medan, Indonesia. Chitosan was used as a starting material. 
The distilled water and universal indicator $\mathrm{pH} \mathrm{0-14}$ were used for the entire experiments.

\section{Synthesis of Chitosan NPs}

The chitosan NPs were prepared using the ionic gelation method with $0.5 \%$ chitosan and $1 \%$ TPP. $0.5 \%$ chitosan was prepared by dissolving $5 \mathrm{~g}$ of chitosan in $1.0 \mathrm{~L}$ of $1 \%$ acetic acid. $1 \%$ TPP was made by dissolving $2.5 \mathrm{~g}$ of TPP in $250 \mathrm{~mL}$ distilled water. Three different volume ratios of chitosan: TPP were made to obtain chitosan NPs. They were $400 \mathrm{~mL}: 80 \mathrm{~mL}$ (volume ratio 20:4), $400 \mathrm{~mL}$ : $60 \mathrm{~mL}$ (volume ratio 20:3) and $400 \mathrm{~mL}: 40 \mathrm{~mL}$ (volume ratio 20:2). The synthesis of the chitosan NPs was started by adding $80 \mathrm{~mL} 1 \%$ TPP solution while stirring drop by drop into a beaker containing $400 \mathrm{~mL}$ of $0.5 \%$ chitosan solution. After it was completed, the stirring process was maintained for $1 \mathrm{~h}$ at room temperature. These steps were repeated for volume ratios of 20:3 and 20:2. Then, the $\mathrm{pH}$ of each suspension was measured.

\section{Characterization of Chitosan NPS}

The chitosan NPs were characterized by PSA to determine the particle size distribution. For FTIR characterization, each suspension was re-dispersed in water and drained of the liquid. This process was repeated several times to remove the traces of acetic acid. Then, the suspension was centrifuged at $4000 \mathrm{rpm}$ for $10 \mathrm{~min}$ to separate the product and liquid. Subsequently, the resulting solid was dried. The solid product of chitosan-TPP was characterized using FTIR to determine their functional groups. Chitosan and TPP as starting materials were also characterized by FTIR.

\section{RESULTS AND DISCUSSION}

The synthesis of chitosan NPs was carried out using the ionic gelation method with a chitosan and TPP solutions [15], [16]. At this stage, the effect of the volume of the TPP solution on the size of the chitosan NPs was evaluated. Chitosan NPs were synthesized using $5 \%$ chitosan and $1 \%$ TPP. The volume ratios of chitosan and TPP in this study were $400 \mathrm{~mL}: 80 \mathrm{~mL}$ (20: 4), $400 \mathrm{~mL}: 60 \mathrm{~mL}$ (20:3), and $400 \mathrm{~mL}: 40 \mathrm{~mL}$ (20:2).

The TPP solution serves as a crosslinking agent. The addition of the TPP solution was carried out slowly drop-bydrop into the $0.5 \%$ chitosan solution so that the crosslinking process took place perfectly. The chitosan solution was clear and then turned white with the addition of the TPP solution. The obtained white solution indicated the successful formation of chitosan NPs (chitosan-TPP).

Chitosan and TPP were initially in the form of solutions where the particle size was $<1 \mathrm{~nm}$. Meanwhile, after mixing a suspension, the chitosan NPs (chitosan-TPP) were formed due to the crosslinking process between chitosan and TPP. This suspension will settle after being left idle. The suspension has a particle size > $100 \mathrm{~nm}$. The resulting suspensions were characterized using PSA to see the size of the particles produced. The results of PSA characterization can be seen in Table 1.
TABLE I. The Distribution OF PARTICLE SizE

\begin{tabular}{|c|c|c|}
\hline $\begin{array}{l}\text { Volume Ratio of } \\
\text { Chitosan: TPP }\end{array}$ & $\begin{array}{c}\text { Particles } \\
\text { Size, d }(\mathbf{n m})\end{array}$ & $\begin{array}{c}\text { Differential } \\
\text { Number, f }(\%)\end{array}$ \\
\hline \multirow[t]{11}{*}{$20: 4$} & 531 & 28 \\
\hline & 572 & 21 \\
\hline & 616 & 15 \\
\hline & 664 & 11 \\
\hline & 715 & 8 \\
\hline & 771 & 6 \\
\hline & 830 & 4 \\
\hline & 895 & 3 \\
\hline & 964 & 2 \\
\hline & 1038 & 1 \\
\hline & $1119-1750$ & $<1$ \\
\hline \multirow[t]{10}{*}{$20: 3$} & 434 & 34 \\
\hline & 470 & 23 \\
\hline & 509 & 15 \\
\hline & 551 & 10 \\
\hline & 596 & 7 \\
\hline & 645 & 4 \\
\hline & 698 & 3 \\
\hline & 755 & 2 \\
\hline & 817 & 1 \\
\hline & $884-1419$ & $<1$ \\
\hline \multirow[t]{10}{*}{$20: 2$} & 283 & 32 \\
\hline & 307 & 22 \\
\hline & 332 & 15 \\
\hline & 360 & 10 \\
\hline & 390 & 7 \\
\hline & 422 & 5 \\
\hline & 457 & 3 \\
\hline & 495 & 2 \\
\hline & 536 & 1 \\
\hline & $580-935$ & $<1$ \\
\hline
\end{tabular}

Based on Table 1, the volume ratio of chitosan-TPP (20:4) resulted in non-uniform particle sizes. Likewise, the volume ratios of chitosan: TPP (20:3) and chitosan: TPP (20:2) also did not produce uniform particle sizes. Based on the data, it can be concluded that the smaller the chitosan: TPP ratio, the smaller the resulting particle size. The distribution of the average particle size in different volume ratios of chitosan: TPP can be seen in Table 2.

TABLE II. The Average Particle Size of Chitosan NPS

\begin{tabular}{|l|l|l|}
\hline $\begin{array}{c}\text { Volume Ratio of } \\
\text { Chitosan: TPP }\end{array}$ & Particle Size (nm) & Polydispersity Index (PI) \\
\hline $20: 4$ & 648 & 0.380 \\
\hline $20: 3$ & 516 & 0.566 \\
\hline $20: 2$ & 340 & 0.426 \\
\hline
\end{tabular}

Based on Table 2, the greater the volume ratio of chitosan: TPP, the larger the particle size produced, which has influenced by the TPP volume. At a small volume of TPP, the particles produced will be smaller. The presence of large amounts of TPP will cause precipitation because the interaction with chitosan occurs easily. Therefore, the probability of the resulting particle size will be greater. The resulting particle size distribution was also indicated by the polydispersity index value (PI). The PI value below 0.05 indicates a highly 
monodispersed system and above 0.70 indicates a very broad particle size distribution [17]. The lower PI value shows the particle size with more uniform size [15]. The polydispersity index also shows the stability of a suspension. The smaller the PI value, the more stable the dispersion system will be [3]. The smallest polydispersity index was in the ratio of 20:4 with a value of 0.38 .

TABLE III. THE MASS OF OBTAINED ChITOSAN-TPP

\begin{tabular}{|c|l|c|c|}
\hline $\begin{array}{c}\text { Volume Ratio of } \\
\text { Chitosan: TPP }\end{array}$ & \multicolumn{2}{c|}{$\begin{array}{c}\text { pH of } \\
\text { Suspension }\end{array}$} & \multicolumn{2}{c|}{ Mass (g) } \\
\cline { 4 - 5 } & 4 & $\boldsymbol{1}$ & $\mathbf{2}$ \\
\hline $20: 4$ & 4 & 0.67 & 0.69 \\
\hline $20: 3$ & 4 & 0.36 & 0.30 \\
\hline $20: 2$ & 4 & 0.18 & 0.05 \\
\hline
\end{tabular}

The resulting solid of chitosan-TPP can be seen in Table 3. The greater the TPP volume added, the more mass of chitosanTPP produced will be. Furthermore, the chitosan-TPP was characterized by FTIR, and the result was depicted in Figure 1. The FTIR spectrum showed the presence of functional groups such as $-\mathrm{OH}$ and amines $\left(3420 \mathrm{~cm}^{-1}\right), \mathrm{C}-\mathrm{H}$ alkanes $\left(2926 \mathrm{~cm}^{-1}\right)$, and $-\mathrm{C}=\mathrm{O}$ groups and amides $\left(1638 \mathrm{~cm}^{-1}\right)$. The absorption band at $1537 \mathrm{~cm}^{-1}$ indicated the presence of $-\mathrm{NH}$ deformation $[5,15]$. In addition, the absorption bands at $894 \mathrm{~cm}^{-1}$ and 1077 $\mathrm{cm}^{-1}$ indicated the existence of $\mathrm{P}-\mathrm{O}$ and $\mathrm{P}=\mathrm{O}$ groups $[15,18]$.

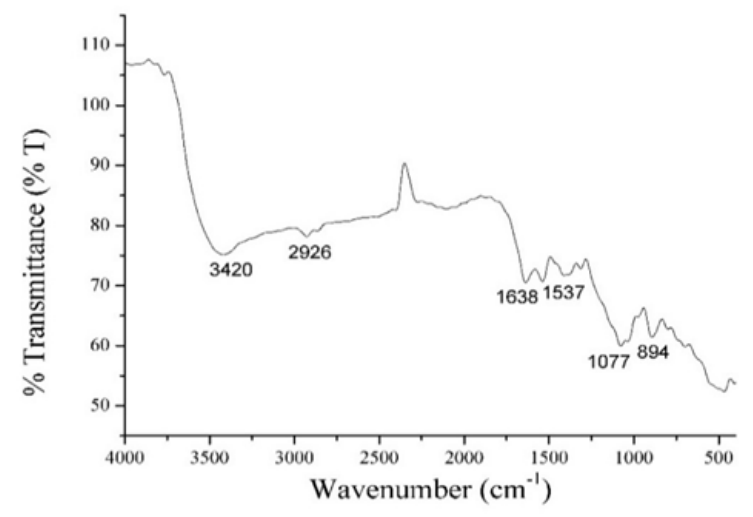

Fig. 1. The FTIR spectrum of chitosan-TPP product.

Based on the analysis of the presence of functional groups, it is known that the synthesized product was a chitosan-TPP compound derived from chitosan, which has undergone a cross-linking process with TPP. The ammonium groups of chitosan have been linked with tripolyphosphoric groups of TPP [5]. The chitosan-TPP particles are insoluble either in water $\left(\mathrm{H}_{2} \mathrm{O}\right)$ or in acetic acid $\left(\mathrm{CH}_{3} \mathrm{COOH}\right)$. It may be caused by amine groups of chitosan that have been linked with tripolyphosphoric groups of TPP so that it is may not possible to form hydrogen bonds. The structure of chitosan-TPP can be seen in Figure 2.

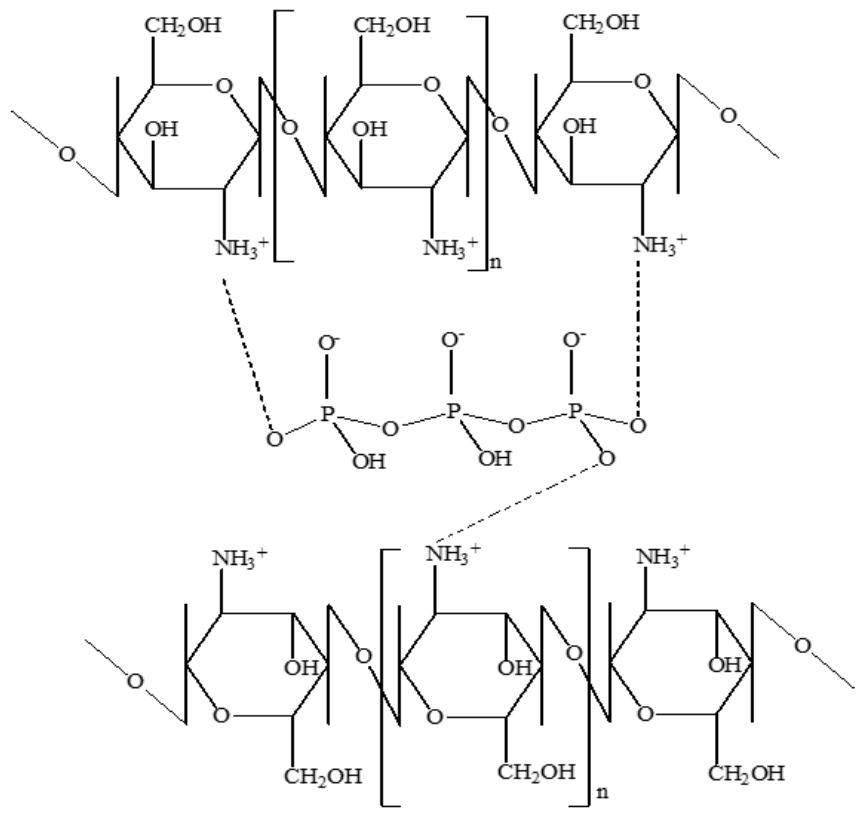

Fig. 2. The structure of chitosan-TPP [17].

The synthesized chitosan-TPP NPs were also shown by the combined FTIR spectral pattern. The FTIR spectrum of the synthesized product has a similar pattern to the standard chitosan, especially in the fingerprint area (around $400 \mathrm{~cm}^{-1}$ $2000 \mathrm{~cm}^{-1}$ ). Also, the region from $2000 \mathrm{~cm}^{-1}$ to $4000 \mathrm{~cm}^{-1}$ has the same spectral pattern. The spectral pattern of the synthesized chitosan-TPP is different from the TPP's FTIR spectrum pattern either in $400 \mathrm{~cm}^{-1}-2000 \mathrm{~cm}^{-1}$ or in $2000 \mathrm{~cm}^{-1}$ $4000 \mathrm{~cm}^{-1}$. The combined FTIR spectrum between standard chitosan, chitosan-TPP, and TPP can be seen in Figure 3.



Fig. 3. FTIR spectra of TPP, chitosan and chitosan-TPP.

\section{CONCLUSIONS}

Based on the research results that have been done, it can be concluded that chitosan NPs have been successfully 
synthesized using the ionic gelation method. The volume ratios between chitosan and TPP affected the average particle size of chitosan NPs. The more TPP has added the bigger size of chitosan NPs will be formed.

\section{ACKNOWLEDGMENTS}

We would like to thank LPPM of Universitas Samudra for research funding with grant No. 562/UN54.6/PG/2020 (Penelitian Dasar Unggulan). We also thank Basic Laboratory at Universitas Samudra and Chemistry Education Laboratory at Universitas Syiah Kuala for providing research facilities.

\section{REFERENCES}

[1] Y. Amri, R. Fajri and M.S. Batu, "Chitosan Isolatiom and Its Application to Reduce the Content of Metal Ions in Wellbore Water," J. Neutrino J. Fis. dan Apl., vol. 12, no. 1, pp. 30-36, 2019.

[2] R.M. Saeed, I. Dmour, and M. O. Taha, "Stable Chitosan-Based Nanoparticles Using Polyphosphoric Acid or Hexametaphosphate for Tandem Ionotropic / Covalent Crosslinking and Subsequent Investigation as Novel Vehicles for Drug Delivery," Front. Bioeng. Biotechnol., vol. 8, pp. 4, 2020.

[3] M.J. Masaruddin, S. M. Cutts, B. J. Evison, D. R. Phillips, and P. J. Pigram, "Factors determining the stability, size distribution, and cellular accumulation of small, monodisperse chitosan nanoparticles as candidate vectors for anticancer drug delivery: application to the passive encapsulation of [14C]-doxorubicin," Nanotechnol. Sci. Appl., vol. 8, pp. 67-80, 2015.

[4] H. Zhang, S. Wu, Y. Tao, L. Zang, and Z. Su, "Preparation and Characterization of Water-Soluble Chitosan Nanoparticles as Protein Delivery System,” J. Nanomater., vol. 2010, pp. 898910, 2010.

[5] D. N. Mohammadpour, R. Eskandari, M. Avadi, H. Zolfagharian, S. A. Mir Mohammad, and M. Rezayat, "Preparation and in vitro characterization of chitosan nanoparticles containing Mesobuthus eupeus scorpion venom as an antigen delivery system," J. Venom. Anim. Toxins Incl. Trop. Dis., vol. 18, no. 1, pp. 44-52, 2012.

[6] L.Y. Ing, N.M. Zin, A. Sarwar, and H. Katas, "Antifungal Activity of Chitosan Nanoparticles and Correlation with Their Physical Properties," Int. J. Biomater., vol. 2012, pp. 632698, 2012.

[7] L. Pilon, P.C. Spricigo, M. Miranda, M.R. de Moura, O.B.G. Assis, L.H.C. Mattoso, and M.D. Ferreira, "Chitosan nanoparticle coatings reduce microbial growth on fresh-cut apples while not affecting quality attributes," International Journal of Food Science \& Technology, vol. 50, no. (2), pp. 440-448, 2015.

[8] N.N. Thinh, P.T.B. Hanh, T.V. Hoang, V.D. Hoang, N. Van Khoi and T. Dai Lam, "Magnetic chitosan nanoparticles for removal of $\mathrm{Cr}(\mathrm{VI})$ from aqueous solution,” Mater. Sci. Eng. C, vol. 33, pp. 1214-1218, 2013.

[9] M. Zulfajri, H.N. Abdelhamid, S. Sudewi, S. Dayalan, A. Rasool, A. Habib, and G.G. Huang, "Plant Part-Derived Carbon Dots for Biosensing," Biosensors, vol. 10, no. 6, pp. 68, 2020.

[10] P. Sanap, V. Hegde, D. Ghunawat, M. Patil, N. Nagaonkar, and V. Jagtap, "Current applications of chitosan nanoparticles in dentistry: A review,” Int. J. Appl. Dent. Sci., vol. 6, no. 4, pp. 81-84, 2020.

[11] T. Chen, S. Chinnapaiyan, S. Chen, M.A. Ali, M.S. Elshikh, and A.H. Mahmoud, "Facile synthesis of copper ferrite nanoparticles with chitosan composite for high-performance electrochemical sensor," Ultrason. - Sonochemistry, vol. 63, pp. 104902, 2020.

[12] M.A. Dheyab, A. A. Aziz, M. S. Jameel, P. M. Khaniabadi, and A. A Oglat, "Rapid Sonochemically-Assisted Synthesis of Highly Stable Gold Nanoparticles as Computed Tomography Contrast Agents," Appl. Sci. vol. 10, p. 7020, 2020

[13] G. Michailidou, N.M. Ainali, E. Xanthopoulou, S. Nanaki, M. Kostoglou, E.N. Koukaras and D.N. Bikiaris, "Effect of poly (vinyl alcohol) on nanoencapsulation of budesonide in chitosan nanoparticles via ionic gelation and its improved bioavailability," Polymers, vol. 12, no. (5), pp. 1101, 2020.

[14] Y. Ciro, J. Rojas, J. Oñate-garzon, and C.H. Salamanca, "Synthesis, Characterisation and Biological Evaluation of Ampicillin-ChitosanPolyanion Nanoparticles Produced by Ionic Gelation and Polyelectrolyte Complexation Assisted by High-Intensity Sonication," Polymers (Basel)., vol. 11, p. 1758, 2019.

[15] N. Othman, M.J. Masarudin, C.Y. Kuen, and N.A. Dasuan, "Synthesis and Optimization of Chitosan Nanoparticles Loaded with L-Ascorbic Acid and Thymoquinone," Nanomaterials, vol. 8, pp. 920, 2018.

[16] H. Bangun, S. Tandiono, and A. Arianto, "Preparation and evaluation of chitosan-tripolyphosphate nanoparticles suspension as an antibacterial agent," J. Appl. Pharm. Sci., vol. 8, no. 12, pp. 147-156, 2018.

[17] M. Danaei, M. Dehghankhold, S. Ataei, F. Hasanzadeh Davarani, R. Javanmard, A. Dokhani, and M.R. Mozafari, "Impact of particle size and polydispersity index on the clinical applications of lipidic nanocarrier systems," Pharmaceutics, vol. 10, no. (2), pp. 57, 2018.

[18] F. Jafary, M. Panjehpour, J. Varshosaz, and P. Yaghmaei, "Stability Improvement of Immobilized Alkaline Phosphatase Using Chitosan," Brazilian J. Chem. Eng., vol. 33, no. 02, pp. 243-250, 2016. 